CASE REPORT

\title{
A case of acute acalculous cholecystitis complicated by primary Epstein-Barr virus infection
}

\author{
Kenichi Suga, Miki Shono, Aya Goji, Sato Matsuura, Miki Inoue, Masami Kawahito, \\ and Kazuhiro Mori \\ Department of Pediatrics, Tokushima Prefectural Central Hospital, Tokushima, Japan
}

\begin{abstract}
Acute acalculous cholecystitis (AAC) is a rare complication of infectious mononucleosis (IM). An immunocompetent 6-year-old Japanese girl complained of epigastralgia during the course of IM. Ultrasonography (US) revealed a markedly thickened and sonolucent gallbladder wall. No gallstones were apparent. Antibodies against Epstein-Barr virus (EBV) confirmed primary EBV infection. Cytomegalovirus immunoglobulin $M$ showed a false-positive result in the acute phase, probably due to cross-reaction to EBV nuclear antigen. We diagnosed her as AAC related with primary EBV infection. She recovered completely by conservative treatment. US should be performed in consideration of the possibility of AAC when a patient with IM complains of epigastralgia. J. Med. Invest. 61 : 426429, August, 2014
\end{abstract}

Keywords : acute acalculous cholecystitis, Epstein-Barr virus, infectious mononucleosis

\section{INTRODUCTION}

Cholecystitis is rare in children. When a patient complains of epigastralgia, pediatricians may consider possibilities such as enterocolitis, duodenal ulcer, and Henoch-Schönlein purpura. On the other hand, infectious mononucleosis (IM) associated with primary Epstein-Barr virus (EBV) infection is very familiar, but diagnosis is sometimes difficult due to the unclear symptoms. IM uncommonly causes complications such as hemophagocytic lymphohystiocytosis, splenic rupture, and encephalitis (1). The present study describes a case of acute acalculous cholecystitis (AAC) associated with IM.

Received for publication April 11, 2014 ; accepted June 6, 2014.

Address correspondence and reprint requests to Kenichi Suga, Department of Pediatrics, Tokushima Prefectural Central Hospital, 1-10-3 Kuramotocho, Tokushima, Tokushima 770-8539, Japan and Fax : +81-88-637-8354.

\section{CASE REPORT}

A 6-year-old Japanese girl was admitted to our hospital with a 10-day history of epigastralgia and low-grade fever. She had visited a local hospital twice and had been subscribed antibiotics for enterocolitis. Her past history was not significant except for dysphonia, leading to speech therapy at the local hospital. She had not previously experienced repeated abdominal pain. Appetite had remained decreased since disease onset. Physical examination showed that body temperature was $37.3^{\circ} \mathrm{C}$, slight facial edema was apparent, the mucous membrane of the pharynx was reddened, and some of the cervical lymph nodes were swollen. Localized tenderness was identified in the right hypochondrium without enlargement of the liver or spleen. Jaundice was not observed in the skin or conjunctiva.

Blood examination showed the following : white blood cell (WBC) count, $13.6 \times 10^{3} / \mu 1$ (atypical lymphocytes, $1.0 \%$ ) ; hemoglobin, $12.2 \mathrm{~g} / \mathrm{dl}$; platelet count, $17 \times 10^{4} / \mu \mathrm{l}$; C-reactive protein level, $0.6 \mathrm{mg} /$ 
$\mathrm{dl}$; aspartate aminotransferase (AST), $184 \mathrm{U} / 1$; alanine aminotransferase (ALT), $139 \mathrm{U} / 1$; lactate dehydrogenase (LDH), $559 \mathrm{U} / 1$; total bilirubin, $0.4 \mathrm{mg} / \mathrm{dl}$; direct bilirubin, $0.1 \mathrm{mg} / \mathrm{dl}$; $\gamma$-glutamyl transferase, $36 \mathrm{U} / 1$; alkaline phosphatase, $506 \mathrm{U} / 1$; and leucine aminopeptidase, $86 \mathrm{U} / 1$. Ultrasonography (US) revealed marked thickening of the gallbladder wall to $4.6 \mathrm{~mm}$ with a sonolucent layer (Fig. 1 A, B). Sludge and pericholecystic fluid was also evident. In addition, localized tenderness was found over the gallbladder, representing a positive sonographic Murphy's sign. No stones or dilatation of the biliary tract were evident. Computed tomography suggested acute hepatitis or cholecystitis with collapse of the gallbladder, edematous gallbladder wall, and periportal collar sign ; edematous inflammation around the portal veins (Figure 2).

AAC was diagnosed based on the ultrasonography findings. A fat-restricted diet and peripheral infusion were initiated. IM was also suspected based on the clinical presentation with edematous eyelids, pharyngitis, lymphadenopathy, and liver injury. On hospital day 3 , the ratio of atypical lymphocytes among leukocytes was elevated to $8 \%$. Titers of antibodies to EBV using an indirect immunofluorescence assay (FA) were increased as follows : EBV-viral capsid antigen (VCA) immunoglobulin (Ig)M $1: 10$; and EBV-VCA-IgG $1:$ : 80. EBV-EBNA (FA) was equivocal due to non-specific reaction. Anti-cytomegalovirus (CMV) antibody levels by enzyme immunoassay were also elevated as follows : CMV-IgM, 3.43 index (normal, 0-0.8) and CMV-IgG, 13.2 index (normal, 0-1.9). Abdominal pain and low-grade fever gradually improved. On hospital day 8 , abdominal pain became mild and blood results improved as follows : WBC count, $11.9 \times 10^{3} / \mu \mathrm{l}$; AST, $46 \mathrm{U} /$ 1 ; ALT, $55 \mathrm{U} / 1$; ALP, $600 \mathrm{U} / 1$; LDH, $477 \mathrm{U} / 1$; and CRP, $0.5 \mathrm{mg} / \mathrm{dl}$. On repeated US, thickening of the gallbladder wall was markedly improved (Fig. $1 \mathrm{C}$. D). The patient was therefore discharged on day 8 .

At the 1 month follow-up, the patient appeared healthy and blood results had all normalized. Followup after 3 months revealed that EBV-IgG (FA) had significantly increased to $1: 320$ and positive results for EBNA were obtained from enzyme-linked immunoassay, whereas CMV-IgM was 1.0 index and CMV-IgG had decreased to 11.7 index.

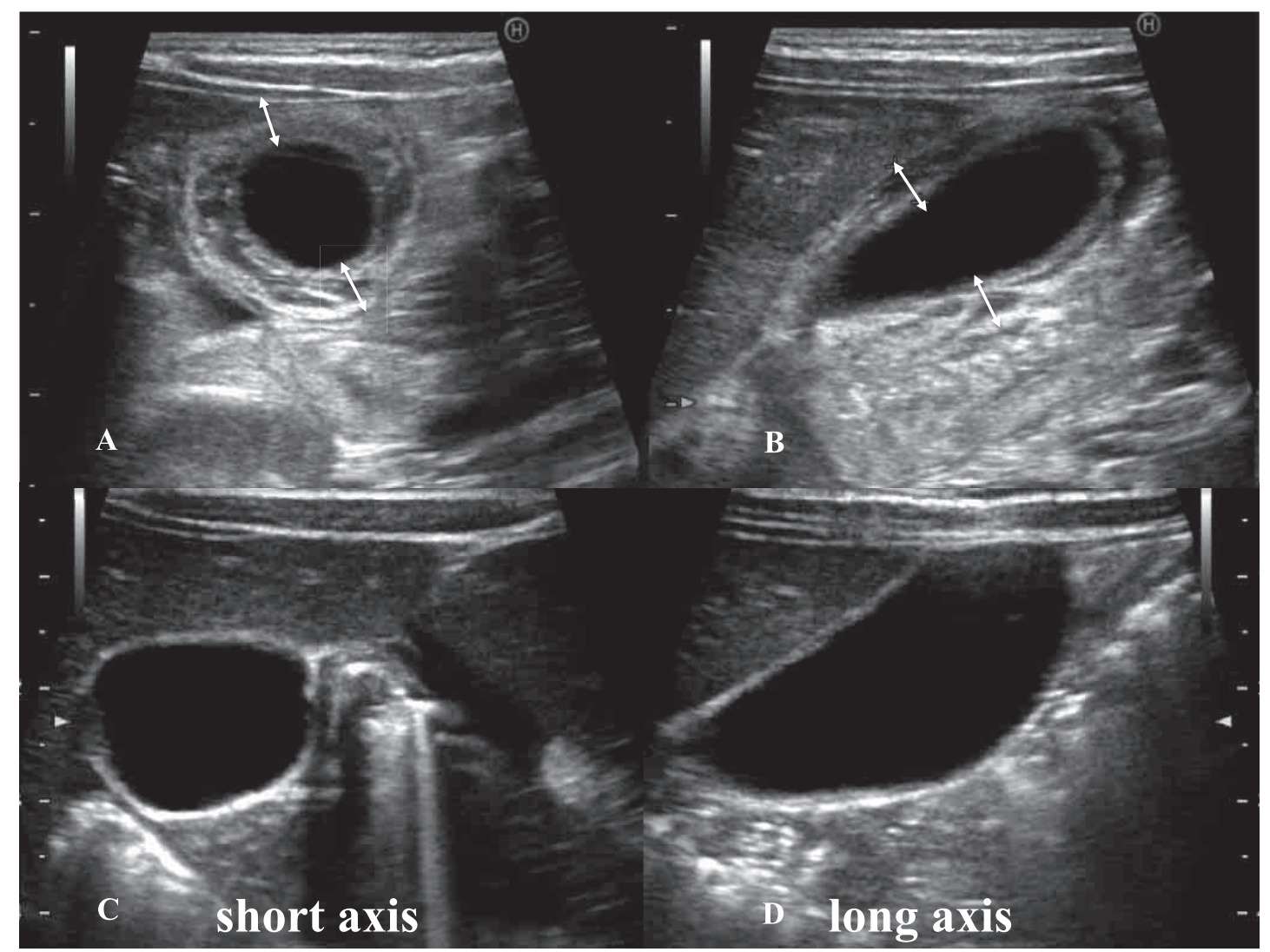

Figure 1. Ultrasonography on admission demonstrates sonolucent thickening of the entire circumference of the gallbladder wall, to $4.6 \mathrm{~mm}$. (A) Horizontal view. B) Sagittal view. ) Thickening of the gall bladder wall appears on ultrasonography to have resolved by hospital day 8. (C) Horizontal view. D) Sagittal view.) 

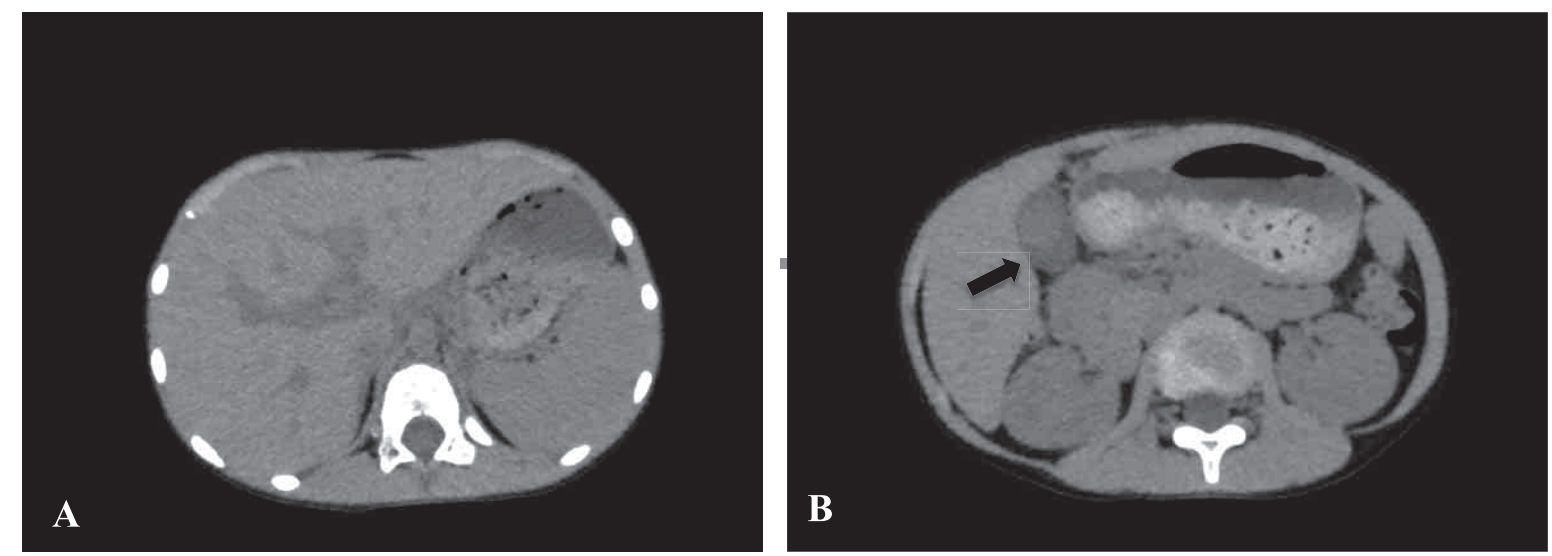

Figure 2. Plain computed tomography on admission suggests acute hepatitis or cholescystitis.

A. Low density area is observed around the portal veins. (Periportal collar sign)

B. Edematous swelling of gallbladder wall was shown by arrow. Low echoic lesions surrounded high echoic lesions in gallbladder.

\section{DISCUSSION}

Acute cholecystitis is a rare disease in children. Most adult patients with cholecystitis show complications of gallstones and require emergency surgery. In children, acute cholecystitis occurs in relation to infection rather than to gallstones. Reported associated pathogens include hepatitis A, Brucella, malaria, and Salmonella $(2,3)$. Some reports have described AAC following systemic diseases, including systemic lupus erythematosus, nephrotic syndrome, and Kawasaki disease $(4,5)$. AAC associated with $\mathrm{EBV}$ infection has also been reported, but as far as we know, only eight child patients, including the present case, have been described $(6,7)$.

US examination allowed definitive diagnosis of AAC. Our patient had been misdiagnosed with enterocolitis until US was performed at our hospital. US of AAC showed thickening of the gallbladder wall $(>3 \mathrm{~mm})$, sludge, sonographic Murphy's sign, and pericholecystic fluid (7). None of these features are specific for AAC, combinations of two or more and clinical symptoms are satisfactory for reaching the diagnosis of AAC (7). Gallbladder wall thickening is also familiar in various nonbiliary disorders ; viral hepatitis without cholecystitis, peritonitis, liver cirrhosis, chronic heart failure, and chronic renal failure (8). The exact pathophysiologic mechanism leading to the gallbladder wall thickness in such conditions is uncertain, but it is likely due to venous occlusion of gallbladder wall by elevated portal venous pressure, decreased intravascular osmotic pressure, or subserosal edema, rather than incomplete gallbladder constriction (8).

The etiology of EBV-associated AAC is unknown.
Dehydration or direct virus invasion to the bile duct is postulated to be related to the pathogenesis (7). Patients with IM sometimes show loss of appetite due to sore throat or malaise. Dehydration may cause cholecystitis due to increased bile viscosity. Two cases of EBV-related AAC with Gilbert's syndrome were recently reported from Greece (9). In the present patient, UGTA gene analysis was not performed because jaundice did not appear.

Most children with EBV-associated AAC present with mild clinical symptoms and good prognosis, whereas adult EBV-associated AAC sometimes progresses to serious conditions such as gallbladder perforation, pulmonary edema, or hepatic failure (10).

Co-infection with EBV and CMV was considered due to the positive IgM for both in the acute phase, but follow-up examinations eventually confirmed primary EBV infection, while CMV infection was ruled out because the CMV IgG titer showed no significant increase. Regrettably, we did not perform CMV-DNA analysis using polymerase chain reaction. A previous report described false-positive results for CMV IgM during primary EBV infection (11). We thus suggest that EBNA might cross-react with CMV IgM, resulting in EBNA showing a nonspecific reaction and CMV IgM showing a falsepositive result.

In conclusion, US should be performed when a patient complains of right upper quadrant pain during the course of IM, in consideration of the possibility of AAC. It makes it possible to avoid unnecessary examinations, treatments, and administration of antibacterial agents.

We declare that conflict of interest is none. 


\section{REFERENCES}

1. Jenson HB. Epstein Barr virus. Nelson textbook of pediatrics. 16 th edition chapter 247 , p977-981.Behman RE, Kiegman RM, Jenson HB (eds)

2. Bouyahia O, Khelifi I, Bouafif F, Mazigh Mrad S, Gharsallah L, Boukthir S, Sammoud EI, Gharbi A : Hepatitis A : a rare cause of acute acalculous cholecystitis in children. Med Mal Infect 38(1) : 34-5, 2008

3. Garel L, Lucaya J, Piqueras J : Acute acalculous cholecystitis owing to salmonella sepsis.. Pediatr Radiol 33(12) : 905-6, 2003

4. Mendonça JA, Marques-Neto JF, Prando P, Appenzeller S : Acute acalculous cholecystitis in juvenile systemic lupus erythematosus. Lupus 18(6) : 561-3, 2009

5. Chen CJ, Huang FC, Tiao MM, Huang YH, Lin LY, Yu HR, Yang KD, Huang YC, Chen CC, Chang WC, Kuo HC : Sonographic gallbladder abnormality is associated with intravenous immunoglobulin resistance in Kawasaki disease. Scientific World Journal. 2012 ; 2012 : 485758.

6. Iaria C, Arena L, Di Maio G, Fracassi MG, Leonardi MS, Famulari C, Cascio A : Acute acalculous cholecystitis as the initial presentation of primary Epstein-Barr virus infection : a new case and a review of literature. Int J Infect Dis 12(4) : 391-5, 2008

7. Imamoğlu M, Sarihan H, Sari A, Ahmetoğlu A : Acute acalculous cholecystitis in children ; Diagnosis and treatment. J Pediatr Surg 37(1) : 369, 2002

8. van Breda Vriesman AC, Engelbrecht MR, Smithuis RH, Puylaert JB : Diffuse Gallbladder Wall Thickening : Differential Diagnosis. Am J Roentenol 188 : 495-501, 2007

9. Attilakos A, Prassouli A, Hadjigeorgiou G, Lagona E, Kitsiou-Tzeli S, Galla A, Stasinopoulou A, Karpathios T: Acute acalculous cholecystitis in children with Epstein-Barr virus infection : a role for Gilbert's syndrome? Int J Infect Dis 13(4) : e161-4, 2009

10. O'Donovan N, Fitzgerald E : Gallbladder wall thickening in infectious mono nucleosis : an ominous sign. Postgrad Med J $72: 299$-300, 1996

11. Park JM, Shin JI, Lee JS, Jang YH, Kim SH, Lee $\mathrm{KH}$, Lee $\mathrm{CH}$ : False positive immunoglobulin $\mathrm{M}$ antibody to cytomegalovirus in child with infectious mononucleosis by Epstein-Barr virus infection. Yonsei Med J 31 ; 50(5) : 713-6, 2009 